\title{
KAJIAN KONTRIBUSI SEKTOR TRANSPORTASI DARAT TERHADAP PENINGKATAN EMISI CO2 SERTA INVENTARISASI KEMAMPUAN SERAPAN RUANG TERBUKA HIJAU DI KOTA KENDARI
}

\author{
Rajab Jandipo Kaebansiha ${ }^{1}$, Laode Muhammad Golok Jaya ${ }^{2}$, Lukas Kano Mangalla ${ }^{3}$ \\ ${ }^{1}$ Pascasarjana Manajemen Rekayasa, Universitas Halu Oleo \\ ${ }^{2}$ Jurusan Teknik Sipil, Fakultas Teknik, Universitas Halu Oleo \\ ${ }^{3}$ JurusanTeknik Mesin, Fakultas Teknik, Universitas Halu Oleo \\ ${ }^{1}$ rajabjandipo@gmail.com
}

\begin{abstract}
ABSTRAK
Tata guna lahan, jaringan infrastruktur jalan dan pergerakan manusia dapat mempengaruhi perkembangan serta peningkatan sistem tranportasi perkotaan. Aktivitas transportasi yang tinggi akan berdampak pada peningkatkan emisi gas buang di udara seperti $\mathrm{CO} 2, \mathrm{CO}, \mathrm{HC}, \mathrm{CH} 4, \mathrm{SO} 2, \mathrm{NO} 2$ dan partikulat yang dapat memicu pencemaran udara. Apabila tidak di imbangi dengan penambahan kawasan Ruang Terbuka Hijau maka daya dukung penyerapan emisi $\mathrm{CO} 2$ menjadi berkurang. Penelitian ini bertujuan untuk menganalisis tingkat emisi $\mathrm{CO} 2$ dari konsumsi bahan bakar kendaraan darat serta daya dukung Ruang Terbuka Hijau dalam menyerap emisi CO2 diKota Kendari. Data primer berupa konsumsi bahan bakar berdasakan penyaluran Terminal Bahan Bakar Minyak di kota kendari, sedangkan luasan Ruang Terbuka Hijau mengacu pada RTH yang dikelola oleh Pemerintah Kota Kendari. Analisis yang digunakan dalam menghitung emisi $\mathrm{CO} 2$ adalah metode "tier 1" yang diterbitkan oleh Intergovernmental Panel on Climate Change (IPCC) 2006, sedangkan analisis kemampuan daya serap RTH menggunakan data luasan pada setiap jenis tutupan lahan. Hasil penelitian ini menunjukan bahwa terjadi peningkatan emisi $\mathrm{CO} 2$ yang signifikan akibat konsumsi bahan bakar kendaraan di Kota Kendari sejak tahun 2015 sampai tahun 2018, dimana tingkat emisi tahun 2015 sebesar 265.910,92 ton/tahun, sedangkan tahun 2018 mencapai 326.039,40 ton/tahun. Luas dan daya dukung Ruang Terbuka Hijau existing tidak mampu menyerap keseluruhan jumlah emisi $\mathrm{CO} 2$ yang disebabkan oleh konsumsi bahan bakar kendaraan darat, dimana jumlah emisi yang mampu diserap pada tahun 2018 sebesar 267.884,74 ton dari total emisi $326.039,40$ ton sehingga Kota Kendari masih membutuhkan RTH seluas 102,9 hektar.
\end{abstract}

Kata kunci: Emisi CO2, Kendaraan Darat, Ruang Terbuka Hijau

\section{ABSTRACT}

Study Of Land Transportation Contribution On The Improvement Of CO2 Emissions And Inventory Of Ability Of Green Open Space Absorption In Kendari City. Land use, road infrastructure networks and human movement can enhance the development and improvement of the transportation system. High transportation activities will increase emissions of $\mathrm{CO} 2, \mathrm{CO}, \mathrm{HC}, \mathrm{CH} 4, \mathrm{SO} 2, \mathrm{NO} 2$ and particulate emissions which can increase air pollution. If it is not balanced with the addition of the Green Open Space area, the carrying capacity of $\mathrm{CO} 2$ emissions will be reduced. This study aims to analyze CO2 emissions from land vehicle fuel consumption and carrying capacity of Green Open Space in saving CO2 emissions in Kendari City. Primary data consist of fuel consumption based on the distribution of fuel terminals in the city of Kendari, while the area of the Green Open Space is in accordance with the green space managed by the Kendari City Government. The analysis used in the calculation of CO2 emissions is the "level 1" method issued by the 2006 Intergovernmental Panel on Climate Change (IPCC), while the analysis of the capacity of green space absorption uses area data on each type of land cover. The results of this study indicate a significant increase in CO2 emissions in vehicle fuel consumption in Kendari City from 2015 to 2018 , where the level of emissions in 2015 amounted to 265,910.92 tons / year, while in 2018 it reached 326,039.40 tons / year. The extent and carrying capacity of the Green Open Space is unable to reduce the amount of CO2 emissions caused by vehicle fuel consumption, while the amount of emissions that can be absorbed in 2018 is 267,884.74 tons of the total emissions of 326,039.40 tons so that the City of Kendari needs to require green space covering an area of 102.9 hectares.

Keywords: $\mathrm{CO} 2$ emissions, land transportation, green open space 


\section{PENDAHULUAN}

Pertumbuhan jumlah kendaraan Di Kota Kendari dalam lima tahun terakhir sebesar 39,76\% dimana jumlah kendaraan bermotor yang terdaftar pada tahun 2014 sebanyak 159.098 unit, sedangkan pada tahun 2018 mencapai 222.355 unit. Peningkatan jumlah kendaraan bermotor tertinggi di Kota Kendari terjadi antara tahun 2015 sampai tahun 2018 yaitu mencapai lebih dari $100 \%$ [1]. Dampak peningkatan jumlah kendaraan darat tersebut menyebabkan perubahan alih fungsi lahan di kota Kendari. Sejak tahun 2003 sampai tahun 2009, telah terjadinya perubahan tutupan lahan di wilayah pesisir Teluk Kendari [2], Pada tahun 2013 sampai tahun 2017, penggunaan lahan bukan pertanian (pemukiman, perkantoran, jalan, dll) di Kota Kendari meningkat sebesar 7,21\%, sedangkan luas kawasan hutan berkurang sebesar $11,43 \%$ [3].

Perubahan alih fungsi lahan baru menjadi lahan terbangun dapat menyebabkan penurunan kualitas lingkungan hidup [4]. Selain penurunan alih fungsi lahan, Aktivitas transportasi yang tinggi akan berdampak pada peningkatkan emisi gas buang kendaraan bermotor berupa $\mathrm{CO} 2$ yang merupakan gas utama yang berkontribusi pada pemanasan global [5]. Salah satu upaya untuk mengendalikan pemanasan global adalah melakukan penstabilan konsentrasi $\mathrm{CO} 2$ di atmosfer pada tingkat yang tidak membahayakan dengan cara menyiapkan ruang terbuka hijau yang memadai [6].

Apabila perubahan alih fungsi lahan ini tidak di imbangi dengan penambahan kawasan Ruang Terbuka Hijau (RTH) maka kecukupan hutan kota dalam menyerap emisi CO2 yang diakibatkan oleh konsumsi bahan bakar kendaraan di Kota Kendari menjadi berkurang sehingga peningkatan pemanasan global akan mempengaruhi kualitas udara.

Dalam mengatasi permasalahan tersebut maka diperlukan sebuah kajian korelasi tingkat pertumbuhan emisi $\mathrm{CO} 2$ terhadap kemampuan daya serap RTH yang terdapat di Kota Kendari.

Tujuan dari penelitian ini adalah untuk menganalisis tingkat emisi $\mathrm{CO} 2$ yang dihasilkan konsumsi bahan bakar kendaraan transportasi darat serta daya dukung Ruang Terbuka Hijau dalam menyerap emisi $\mathrm{CO} 2$ di Kota Kendari.

\section{METODE}

\section{Lokasi Penelitian}

Penelitian ini dilaksanakan di Kota Kendari, Provinsi Sulawesi Tenggara.

\section{Bahan Penelitian}

Data yang digunakan dalam kajian ini adalah:

1. Data historis penggunaan bahan bakar di sektor transportasi darat

2. Data kondisi transportasi di Kota Kendari saat ini, diantaranya moda transportasi, jumlah kendaraan bermotor, statistik transportasi darat.

3. Data koefisien emisi $\mathrm{CO} 2$ yang mengacu pada Intergovernmental Panel on Climate Change (IPCC).

4. Data Peta Kota Kendari dan Sebaran Luas Ruang Terbuka Hijau.

\section{Analisis Data}

Penelitian ini digunakan sebuah pendekatan rasionalistik yang bersumber pada sebuah fakta dan didukung oleh teori. Metode analisa dalam penelitian ini adalah metode kuantitatif (perhitungan matematis). Model analisis yang digunakan dalam menghitung tingkat emisi $\mathrm{CO} 2$ adalah metode "tier 1" [7], sedangkan analisis kemampuan daya serap Ruang Terbuka Hijau (RTH) digunakan data luasan setiap jenis tutupan lahan.

Untuk menghitung persentase pertumbuhan jumlah kendaraan dan konsumsi bahan bakar, persamaan yang digunakan dalam menganalisis data adalah analisis dasar geometik menurut persamaan 1 dan persamaan 2 [8].

$$
\begin{aligned}
& P_{t}=P_{0}(1+r)^{t} . \\
& r=\left(\frac{P_{t}}{P_{0}}\right)^{1 / t}-1
\end{aligned}
$$

\section{Dimana :}

$\mathrm{P}_{\mathrm{t}}=$ Jumlah pada tahun $\mathrm{t}$

$\mathrm{P}_{0}=$ Jumlah pada awal tahun

$\mathrm{r} \quad$ Laju pertumbuhan

$\mathrm{t} \quad=$ Periode waktu

Emisi CO2 merupakan zat atau unsur hasil dari sisa hasil pembakaran bahan bakar baik yang dilakukan 
di dalam ruang mesin bakar dalam maupun diluar mesin bakar yang dilepaskan ke udara [9]. Hubungan antara emisi dan pembakaran bahan bakar dinyatakan dalam persamaan 3 [7]:

$$
\mathrm{E} \quad=\sum \text { (fuela } \mathrm{x} \mathrm{EFa} \text { ) }
$$$$
\text { Fuela = Jumlah BBM x energy content }
$$

\section{Dimana :}

$$
\begin{array}{ll}
\text { Jumlah Bahan Bakar }= & \text { liter } \\
\text { Nilai Kalor gasoline* } & 33 \times 10-6 \mathrm{TJ} / 1 \\
\text { Nilai Kalor solar } & =36 \times 10-6 \mathrm{TJ} / 1 \\
\text { Fuela } & \text { Jumlah Bahan } \\
& \text { Bakar }(\mathrm{TJ}) \\
\mathrm{EFa} & \text { Nilai emisi CO2 } \\
& \text { bahan bakar }(\mathrm{kg} / \mathrm{TJ}) \\
\mathrm{E} & =\text { Emisi CO2 }(\mathrm{kg}) \\
\mathrm{a} & \text { Jenis bahan bakar } \\
& \text { (bensin, solar, dll) }
\end{array}
$$

Salah satu fungsi Ruang Terbuka Hijau (RTH) adalah sebagai penyerap $\mathrm{CO} 2$ yang terdapat diudara. Jumlah emisi CO2 yang mampu diserap oleh Ruang Terbuka Hijau dinyatakan dalam persamaan 4 :

$$
\begin{array}{ll}
\text { CO2 Terserap }= & \sum \text { Emisi Aktual - } \\
& \sum \text { RTH Existing } .
\end{array}
$$

$$
\begin{aligned}
\text { Dimana : } & \\
\sum \text { Emisi Aktual }= & \text { Total emisi CO2 dari } \\
& \text { pembakaran bahan bakar } \\
& (\text { ton/tahun }) \\
\sum \text { RTH Existing }= & \text { Total daya serap RTH } \\
& (\text { ton/tahun } / \text { ha) }
\end{aligned}
$$
$\sum$ Emisi Aktual $=$ Total emisi $\mathrm{CO} 2$ dari pembakaran bahan bakar (ton/tahun)

\section{HASIL DAN PEMBAHASAN}

\begin{tabular}{|c|c|c|c|c|c|c|}
\hline \multirow{2}{*}{$\mathbf{T}$} & \multicolumn{2}{|c|}{$\begin{array}{l}\text { Sedan / Jeep } \\
\text { / St. Wagon }\end{array}$} & \multicolumn{2}{|c|}{$\begin{array}{c}\text { Truk } \\
\text { Barang }\end{array}$} & \multicolumn{2}{|c|}{ Pick Up } \\
\hline & $\mathbf{P}$ & $\begin{array}{c}\mathbf{r} \\
(\%)\end{array}$ & $\mathbf{P}$ & $\begin{array}{c}\mathbf{r} \\
(\%)\end{array}$ & $\mathbf{P}$ & $\begin{array}{c}\mathbf{r} \\
(\%)\end{array}$ \\
\hline 2015 & 2,035 & & 929 & & 5,878 & \\
\hline & & -3.39 & & -4.31 & & 10.07 \\
\hline 2016 & 1,966 & & 889 & & 6,470 & \\
\hline 2017 & 2,461 & & 996 & 12.04 & 8,175 & 26.35 \\
\hline 2018 & 1,874 & -23.85 & 957 & -3.92 & 7,333 & -10.30 \\
\hline & & -0.69 & & 1.27 & & 8.71 \\
\hline
\end{tabular}

\section{Laju Pertumbuhan Kendaraan $(P)$}

Berdasarkan penerimaan objek pajak yang dikeluarkan oleh UPTD Samsat Kota Kendari, jenis

\begin{tabular}{|c|c|c|c|c|c|c|}
\hline \multirow[t]{2}{*}{$\mathbf{T}$} & \multicolumn{2}{|c|}{$\begin{array}{l}\text { Mikro bus } \\
\text { (angkot,mik } \\
\text { rolet) }\end{array}$} & \multicolumn{2}{|c|}{$\begin{array}{l}\text { Mini bus } \\
\text { / bus }\end{array}$} & \multicolumn{2}{|c|}{ Motor } \\
\hline & $\mathbf{P}$ & $\begin{array}{c}\mathbf{r} \\
(\%)\end{array}$ & $\mathbf{P}$ & $\begin{array}{c}r \\
(\%)\end{array}$ & $\mathbf{P}$ & $\begin{array}{c}\mathbf{r} \\
(\%)\end{array}$ \\
\hline 2015 & 13,395 & & 775 & & 64,989 & \\
\hline 2016 & & & & & & \\
\hline 2017 & 19,563 & & 773 & & 83,515 & \\
\hline 2018 & 19,985 & 2.16 & & 1.03 & 72,430 & -13.27 \\
\hline & & 14.70 & & 0.34 & & 5.00 \\
\hline
\end{tabular}
kendaraan dibagi dalam 4 (empat) kelompok yaitu mobil penumpang, mobil barang, mobil bus dan sepeda motor diperoleh volume selama 4 tahun (2015-2018).

Data jumlah kendaraan akan digunakan untuk mengetahui presentase peningkatan pertumbuhan jumlah setiap jenis kendaraan pada suatu wilayah dalam setiap tahun, sehingga prediksi jumlah kendaraan pada tahun mendatang dapat diketahui.
Tabel 1. Pertumbuhan Geometrik Kendaraan Sedan, Truk dan Pick Up Tahun 2015 - 2018

Tabel 2. Pertumbuhan Geometrik Mikro Bus, Mini Bus/Bus dan Motor Tahun 2015 - 2018

Berdasarkan tabel 1 dan tabel 2 diatas, peningkatan jenis kendaraan yang tertinggi secara berturut-turut adalah Mobil Pribadi $14.7 \%$, Pick up $8.71 \%$, Sepeda Motor 5\%, Truck $1.27 \%$ dan bus sebesar $0.34 \%$. Sementara jenis kendaraan Sedan pada empat tahun terakhir mengalami penurunan sebesar $0.69 \%$.

\section{Konsumsi Jenis Bahan Bakar Kendaraan (a)}

Berdasarkan data penyaluran Termminal Bahan Bakar Minyak (TBBM), terdapat empat jenis bahan bakar yang digunakan oleh kendaraan darat di Kota Kendari pada tahun 2015 hingga tahun 2018 yaitu Bensin, Pertalite, Pertamax dan Solar. Data jumlah konsumsi bahan bakar kendaraan akan digunakan sebagai dasar perhitungan peningkatan jumlah konsumsi bahan bakar. Selain itu data konsumsi 
bahan bakar akan digunakan untuk menganalisis peningkatan emisi akibat dari pembakaran bahan bakar tersebut.

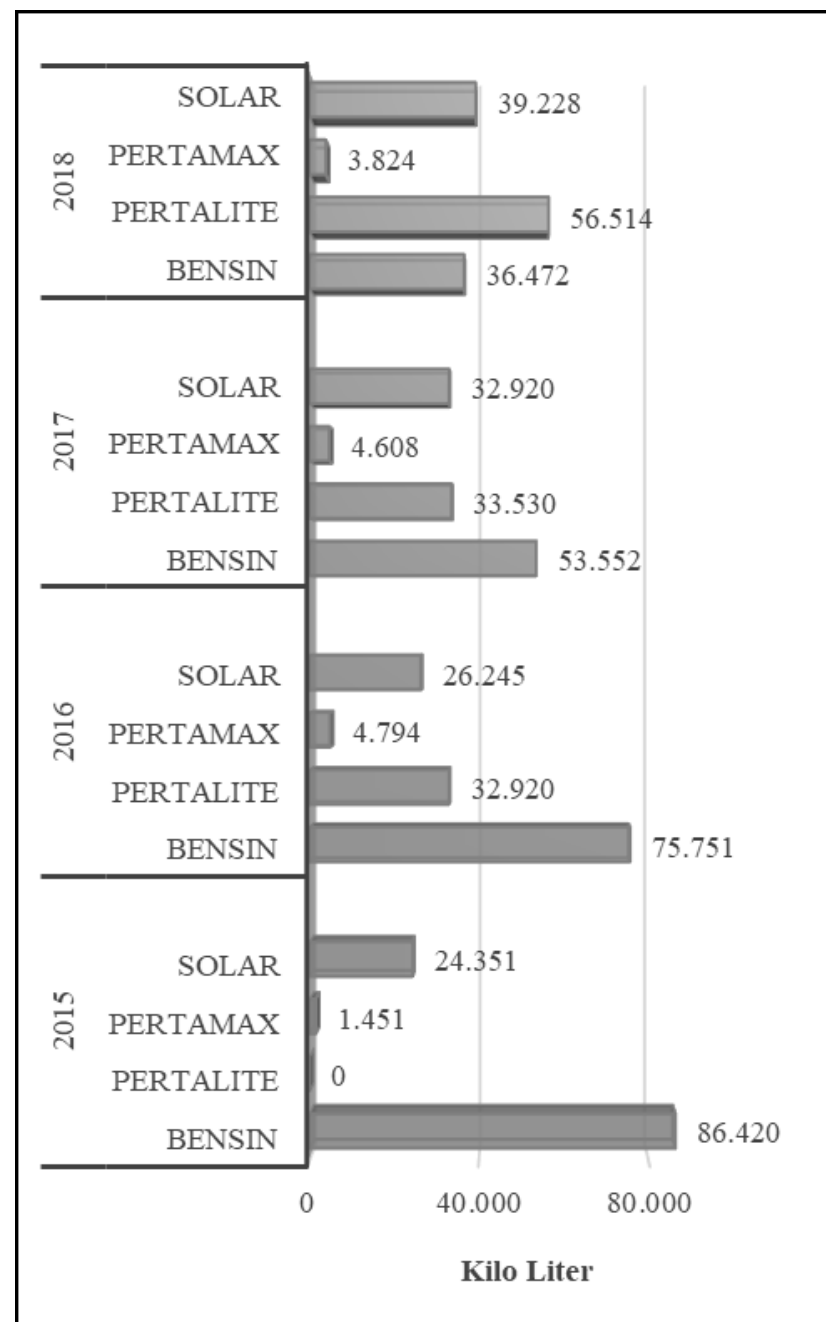

Gambar 1. Grafik Konsumsi BBM Kota Kendari Tahun 2015-2018

\section{Emisi CO2 Dari Penggunaan Bahan Bakar $(E)$}

Jumlah konsumsi bahan bakar pada suatu wilayah akan mempengaruhi jumlah emisi $\mathrm{CO} 2$ yang dihasilkan oleh setiap pembakaran bahan bakar. Semakin banyak jumlah penggunaan bahan bakar maka semakin meningkat pula dampak emisi yang dihasilkan. Dalam menghitung jumlah emisi dari pembakaran bahan bakar kendaraan metode pendekatan yang digunakan adalah metode Tier 1 dengan mengambil rujukan pada dokumen IPCC Tahun 2006.

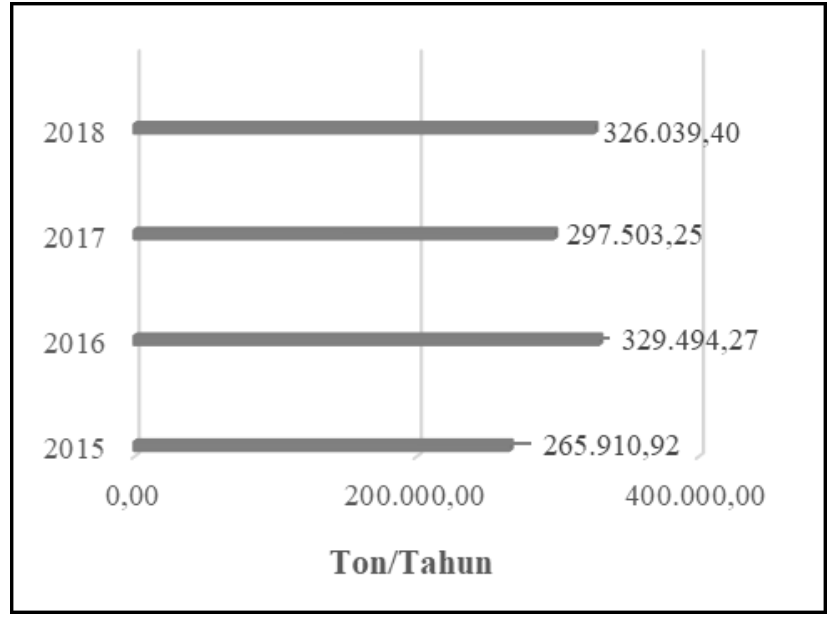

Gambar 2. Grafik Emisi Penggunaan BBM

Transportasi Darat di Kota Kendari Tahun $2015-2018$

\section{Faktor Emisi Spesifik Kendaraan (FES)}

Dalam penentuan Faktor Emisi Spesifik (FES) pada setiap jenis kendaraan, data jumlah kendaraan sangat dibutuhkan untuk membagi emisi yang diakibatkan oleh penggunaan bahan bakar. Data jumlah kendaraan dalam satu unit akan dikonversi dalam Satuan Mobil Penumpang (SMP). Konversi SMP pada setiap jenis kendaraan mengacu pada peraturan Dirjen Bina Marga Tahun 1997 maupun MKJI 1993.

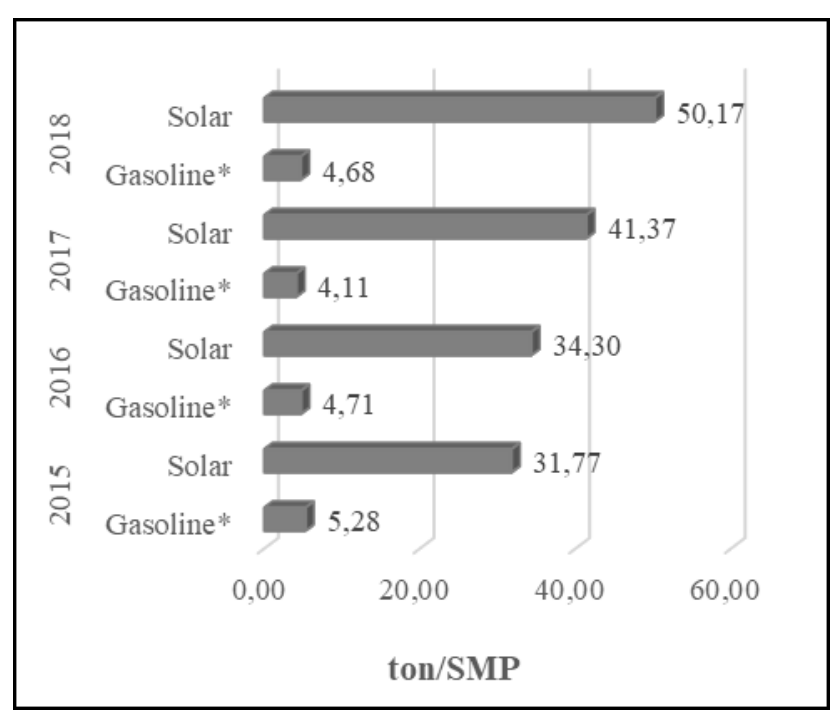

Gambar 3. Grafik Faktor Emisi Spesifik Dalam Setiap SMP 2015 - 2018

Gambar 3 diatas menunjukan bahwa Faktor Emisi Spesifik (FES) dari kendaraan darat yang menggunakan bahan bakar solar lebih tinggi dibandingkan dengan kendaraan yang menggunakan 
bahan bakar gasoline. Kontribusi emisi $\mathrm{CO} 2$ pada kendaraan berbahan solar pada tahun 2018 sebesar 50.17 ton/SMP sedangkan kendaraan berbahan bakar gasoline sebesar 4.68 ton/SMP.

\section{Daya Serap Ruang Terbuka Hijau (RTH)}

Dalam penelitian yang telah dilakukan sebelumnya, penentuan daya serap Ruang Terbuka Hijau untuk menyerap $\mathrm{CO} 2$ yang ada, diperlukan luasan RTH pada setiap jenis tutupan lahan yang ada sehingga kemampuan serapan pada RTH existing dapat diketahui [10].

Lokasi sebaran Ruang Terbuka Hijau existing yang terdapat di Kota Kendari dapat dilihat pada gambar 4, sedangkan luas masing-masing tutupan lahan dapat dilihat pada gambar 5 .

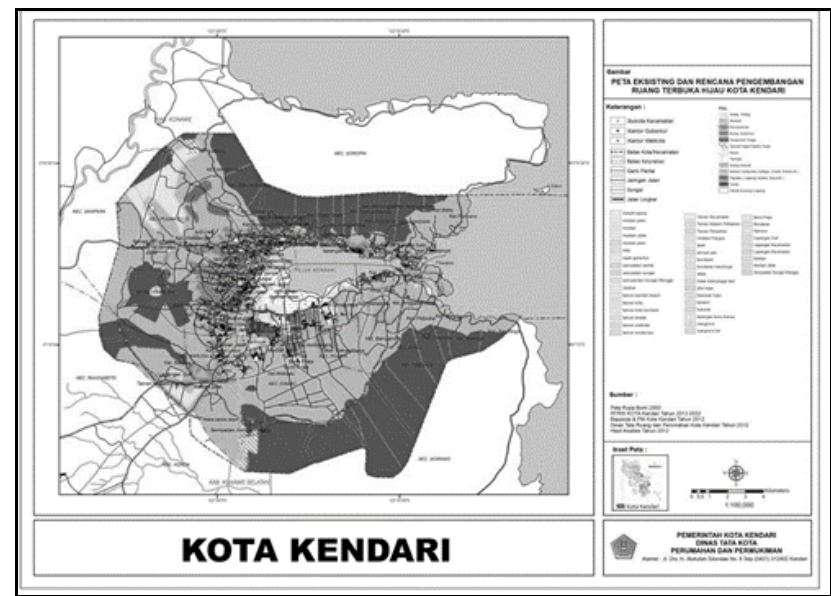

Gambar 4. Peta Sebaran RTH Existing di Kota Kendari (Sumber : Dinas Tata Kota dan Bangunan Kota Kendari)

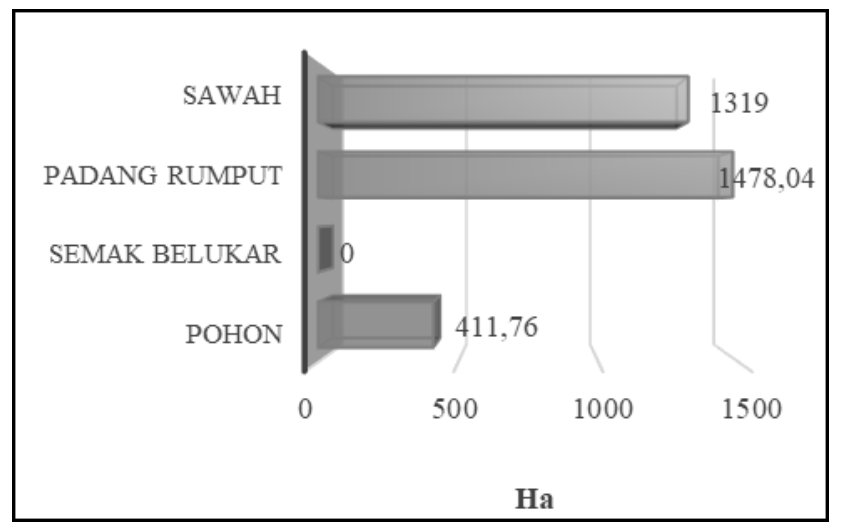

Gambar 5. Grafik Luas RTH Existing Kota Kendari

Berdasarkan gambar 5 diatas, terdapat tiga jenis tipe penutupan lahan yang dapat menyerap kandungan emisi C02 di Kota Kendari dengan luas masing- masing tutupan yaitu pohon 411,76 ha, padang rumput 1.478, 04 ha serta sawah seluas 1.319 ha. Bila dibandingkan dengan luas wilayah, RTH Existing Kota Kendari hanya $11,81 \%$ dari total luas wilayah sebesar 27.176 ha. Apabila mengacu pada Undang-Undang No.26 Tahun 2007 Tentang Penataan Ruang, dimana ruang terbuka hijau yang ideal paling sedikit $30 \%$ dari luas wilayah maka kota Kendari masih kekurangan sebesar 18,19\%.

Kemampuan serapan emisi $\mathrm{CO} 2$ pada setiap jenis tutupan lahan berbeda-beda. Kemampuan serapan masing-masing jenis tutupan lahan existing yang ada di Kota Kendari dapat dilihat pada gambar 6 berikut.

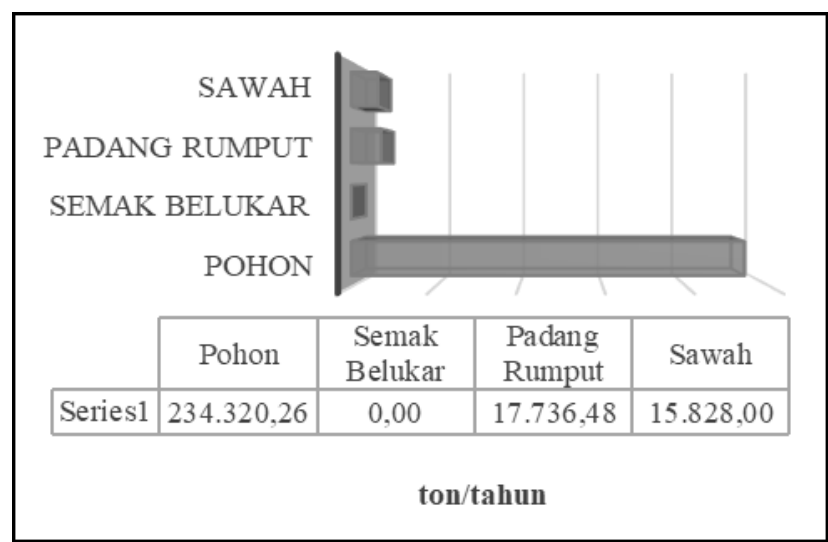

Gambar 6. Kemampuan Serapan RTH Existing Terhadap CO2 Kota Kendari

Berdasarkan tabel 4 diatas, jenis tutupan lahan pohon memiliki daya serap yang tinggi. Vegetasi pohon mampu menyerap emisi sebesar 234.320,26 ton/tahun, padang rumput sebesar 17.736,48 ton/tahun dan sawah sebesar $15.828,00$ ton/tahun.

Bila mengacu pada jumlah emisi $\mathrm{CO} 2$ dari konsumsi bahan bakar pada tahun 2018 terhadap kemampuan serapan RTH existing yang tersedia di Kota Kendari, maka total emisi yang terserap dapat dilihat pada gambar 7 berikut. 


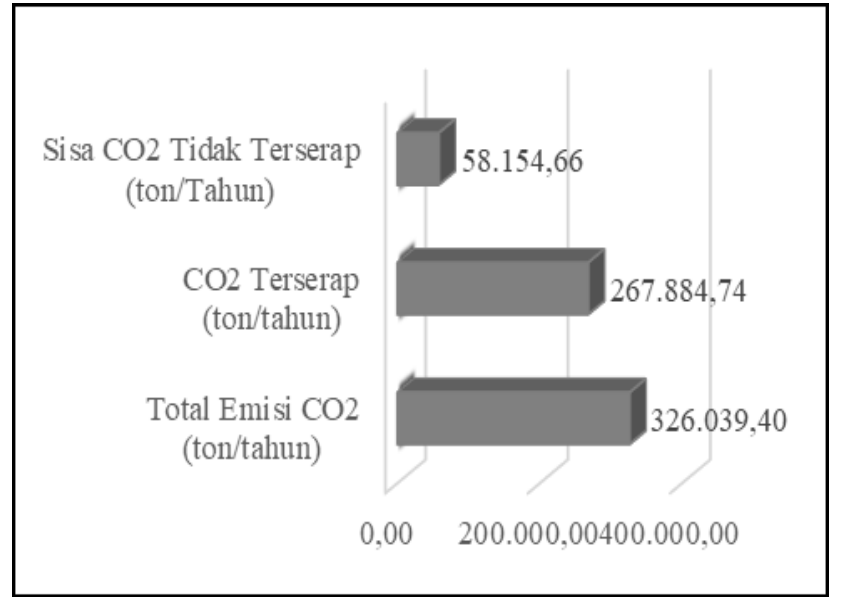

Gambar 7. Grafik Emisi CO2 Terserap

Berdasarkan gambar 7 diatas, jumlah emisi yang mampu diserap oleh RTH existing sebesar $267.884,74$ ton/tahun sedangkan emisi yang tidak terserap sebesar 58.154,66 ton. Dari hasil analisis perbandingan antara jumlah emisi $\mathrm{CO} 2$ dengan $\mathrm{RTH}$ yang tersedia, jumlah emisi yang dapat diserap hanya sebesar $82.16 \%$ dari total emisi sebesar $326.039,40$ ton sehingga pada tahun 2018 di Kota Kendari masih kekurangan RTH sebesar 102.19 ha untuk menyerap emisi $\mathrm{CO} 2$ dari kosumsi bahan bakar pada aktivitas transportasi darat.

\section{KESIMPULAN}

Kontribusi Emisi CO2 yang diakibatkan oleh konsumsi bahan bakar kendaraan transportasi darat di Kota Kendari mengalami peningkatan yang sangat signifikan pada empat tahun terakhir, dimana pada tahun 2015 sebesar 265.910,92 ton/tahun, sedangkan tahun 2018 mencapai 326.039,40 ton/tahun. Dari jumlah emisi yang dihasikan, Luas dan daya dukung Ruang Terbuka Hijau existing di Kota Kendari tidak mampu menyerap keseluruhan jumlah peningkatan emisi $\mathrm{CO} 2$ yang disebabkan oleh konsumsi bahan bakar kendaraan darat, dimana jumlah emisi yang mampu diserap pada tahun 2018 sebesar 267.884,74 ton dari total emisi 326.039,40 ton sehingga kota Kendari masih membutuhkan RTH dengan tipe tutupan lahan pohon seluas 102,9 ha.

\section{DAFTAR PUSTAKA}

[1] Sulawesi Tenggara Dalam Angka 2018, Kendari: BPS, 2018.

[2] L. M. Golok Jaya, "Analisis Perubahan Tutupan Lahan di wilayah Pesisir Teluk Kendari Menggunakan Citra Satelit Resolusi Tinggi (kurun waktu 2003-2009)," Teknik Sipil, 2013.

[3] Kota Kendari Dalam Angka 2018, Kendari: BPS Kota Kendari, 2018.

[4] A. A. Putra, "Estimasi Tingkat Kebisingan Lalu Lintas Dengan Metode Transport Road and Research Laboratory (TRRL) Pada Kawasan Senapati Land," Teknik Sipil, vol. 10, 2012.

[5] Shashank Bharadwaj. et all, "Impact Of Congestion On Greenhouse Gas Emissions For Road Transport In Mumbai Metropolitan Region," Elsevier Ltd, vol. 25, 2017.

[6] E. Dahlan, Hutan Kota : Untuk Pengelolaan dan Peningkatan Kualitas Lingkungan Hidup, Jakarta, Indonesia: Asosiasi Pengusaha Hutan Indonesia (APHI), 1992.

[7] IPCC, "Guidelines for National Greenhouse Gas Inventories," Energy, vol. 2, 2006.

[8] Sembiring. RK, Demografi, Jakarta, Indonesia: Fakultas Pasca Sarjana IKIP, 1985.

[9] Thandjung, Polusi Emisi Gas Buang Bahayakan Kehidupan, Jakarta, Indonesia: Pikiran Rakyat, 2002.

[10] I. W. Murti, "Inventarisasi dan Penentuan Kemampuan Serapan Emisi CO2 Oleh Ruang Terbuka Hijau di Kabupaten Sidoarjo, Jawa Timur," Environmental Engineering, 2015. 